\title{
The necessity of storage technology development for unpredictable energy sources
}

\author{
Maria Daniela Stochitoiu ${ }^{1 *}$, Ilie Utu ${ }^{1}$, and Leon Pana ${ }^{2}$ \\ ${ }^{1}$ University of Petrosani, Department of ACIEE, str.Universitatii 20, Petrosani, Romania \\ ${ }^{2}$ Academia Navala "Mircea cel Batran” , Department of IEEN, str.Fulgerului 1,Constanta, Romania
}

\begin{abstract}
The renewable energy is more and more used and represents a higher and higher percentage in the world's total energy production. The reliability of the renewable sources proves to be less predictable than the conventional ones. The need of new energy storage systems becomes imperative, and when used altogether with renewable sources, they improve the predictability of those sources, thus making possible their use in the energy system market.
\end{abstract}

\section{Introduction}

Worldwide demand for energy is driving increased use of renewable energy sources over the fossil fuel based energy production, due to the limited resources of fossil fuels and the green gas effect generated by use of fossil fuels. Developing technical solutions for increasing the power production from RES (renewable energy solutions) represents a public interest.

In Europe, the renewable sources, like wind and solar, have been accounted for about $38 \%$ of the total energy in 2020 generated by the twenty-seven member states in 2020 , while the fossil fuel resources (coal and natural gas) have been accounted for about $37 \%$. This overtaking occurred in the same time with COVID pandemic restrictions, which accounts for about $4 \%$ reduction in energy consumption. In 2020, the coal based energy production has been reduced with about $20 \%$ (half level of 2015 production), while energy generated from renewable sources has doubled in the last five years. [1;2]

The problem of storage of conventional energy sources, like oil, coal, accumulation lakes, has been discussed since the electrical systems have been developed when considering the unpredictability of the electrical load. The hydroelectric power plants with accumulation lakes and hydropower plants with pumped accumulation lakes provide the traditional energy reserve for covering the sudden load demands.

Nowadays, renewable energy storage systems have been developed side by side with development of power electronics conversion systems and control systems based on modern devices. Also, there are being developed new chemical materials and battery solutions which allow energy storage in larger and larger quantities.

\footnotetext{
*danielastochitoiu@upet.ro
} 


\section{The storage system evolution}

The main energy storage systems and their forecast are shown in the Table 1.

Table 1.

\begin{tabular}{|c|c|c|c|c|c|}
\hline Storage system & Research & Develop & Eloquent & Application & $\begin{array}{c}\text { Mature } \\
\text { technology }\end{array}$ \\
\hline Li-Ion battery & & & & $\rightarrow------b$ & \\
\hline Redox & & & & $\longrightarrow---\rightarrow$ & \\
\hline Na-Ion battery & & & & $-----\rightarrow$ & \\
\hline $\begin{array}{l}\mathrm{NaS} / \mathrm{Na} \quad \text { beta } \\
\text { battery }\end{array}$ & & & & $---->$ & \\
\hline Metal-air battery & & & & & \\
\hline $\begin{array}{l}\text { Semiconductor } \\
\text { coils }\end{array}$ & & $\Rightarrow---1$ & & & \\
\hline Steering wheel & & $=$ & & $\longrightarrow----b$ & \\
\hline CAES & & & & & $\longrightarrow$ \\
\hline Lead battery & & & & - & $\rightarrow$ \\
\hline Hydro CHEAP & & & & & $\longrightarrow$ \\
\hline
\end{tabular}

Li-ion battery technology provides the highest level of energy density $(250 \mathrm{Wh} / \mathrm{kg})$ of the all state-of-art energy storage technologies. Due to the fast charge and wide operating temperature range $\left(-50^{\circ} \mathrm{C} \div 125^{\circ} \mathrm{C}\right)$, Li-ion is currently the best choice of cell designs and chemistries. In the REDOX systems (oxidation reduction) the energy is stored in chemical form in a different, specifically attractive, technology. Anionic redox transitioning to metal oxides, has gained much attention in the recent years for establishing processes and higher energy density with similar electrolyte formulation, to make it key direction in materials research for next generation Li-ion batteries [3;4]. The advanced generation of Li-ion batteries will be deployed before the next generation of solid-state batteries, as it is ideal for use in applications such as storage systems for renewables energy where high energy, high power and high level of safety are mandatory demands.

The conversion of electric energy in chemical energy can be realised through unlimited cycles with a high conversion efficiency, but the demanding costs for this type of storage, of about $2500 \$ / \mathrm{kWh}$, led to its limited applications in the electric power systems.

The energy storage is based on chemical reactions occurring within the secondary batteries. The chemical energy is transformed in electrical energy through reduction reactions. Such solutions have a lower cost, but the energy density is relative reduced to $30-40 \mathrm{Wh} / \mathrm{kg}$, the number of charge-discharge cycles is also reduced (500-800), and their life time is dependent of the operating mode (5-10 years).

While lead acid batteries can be widely used in energetic systems, these are not adequate for large capacity energy storage for utilities systems. Specialized studies about lead acid based batteries are looking to improve their operating characteristics and to improve the suitability in various climates.

Compressed AIR Energy Storage (CAES) are mature storage systems with applicability in power domain (as $100 \mathrm{MW}$ ). The compressed air represents a potential source of energy which can be used in every moment. CAES involves use of large dimension, sealed caverns that limits the use of this solution.

The energy storage based on flywheel systems is relatively reduced and can be used only for short period of time. The initial cost is high but the advantages may be overcoming: there is no environmental pollution, small area of installation, high efficiency, high density of energy $\left(>20 \mathrm{kWh} / \mathrm{m}^{3}\right)$, fast response to disturbances, long life time, reduced maintenance and high reliability [3;5]. These characteristics lead to its increased use, 
especially for limiting the perturbations from energy quality indicators, such as short voltage interruption and voltage gaps.

Supercapacitors incorporate electrostatic energy storage base elements, being configurated as batteries, with different size and modules, for a large spectrum of voltages, power and energy applications. Supercapacitors offer: hundreds of thousands of chargedischarges cycles without degradation, can cover the energy needs due to sudden increase of electrical load demand, with a short response time (ms), however they have in general reduced power capabilities., although the new types of electrochemical supercapacitors are showing some increased power capabilities

Superconducting magnetic energy storage (SMES) accumulates the energy in the magnetic field of a spiral coil in direct current. In the superconducting stage, the conductor resistance becomes zero when the temperature is lower than critical temperature. For example, the $\mathrm{NbTi}$ alloy becomes superconductor at $4,2 \mathrm{~K}$ temperature equivalent liquid helium. The technical literature shows that superconducting phenomena appearance at $77 \mathrm{~K}$ $\left(-196^{\circ} \mathrm{C}\right)$ for several superconductor elements. There have been operating systems with accumulated energy of 20-40MWh, which assures demanded power of (10..20 MW) for couple hours on fast answer [4;6].

Due to to the zero- $\mathrm{CO}_{2}$ emission regulations, utilizing fuel cells as generators raises concerns in society. Fuel cells based on reverse electrolysis processes are using Hydrogen as storage element. One of the scenarios that can be an efficient solution is based on Hydrogen production from electrolysis, using renewable energy sources (RES) during the no load periods, but in the peak load periods, the stored hydrogen produces in the fuel cells the electrical energy which is delivered in the electric grid. Considering efficiency of about $50 \%$, the fuel cells would be more efficient than CHEAP (hydropower plant accumulation with pumping). The fuel cells can be placed closer to RES (renewable energy sources) and together are capable to provide superior energy characteristics within the electro energetic system.

\subsection{Storage system connection to the electric grid}

Majority of the electric energy storage systems provide a DC voltage at their terminals. So, either in the charging process as well as in the energy supply process it is necessary the convert alternative current in direct current and vice-versa. The diagram for connecting a storage system to an electrical grid is shown in (figure 1).

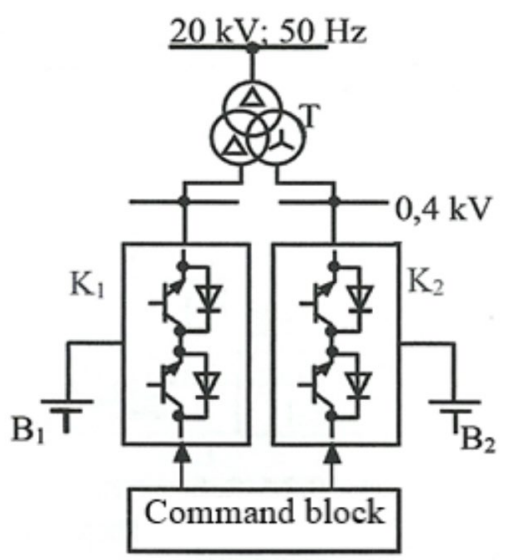

Fig.1 The scheme of connecting a storage system to an electric grid 
During the charging process, the converters $\mathrm{K}_{1}$ and $\mathrm{K}_{2}$ are operating as rectifier and during the energy supply stage the converters are working as inverters. The converters are controlled by a command block.

For limiting the harmonic disturbances that are inherent in the conversion process, a transformer with two secondary windings (one in star connection and one in delta connection) is necessary. The harmonics with -levels smaller than eleven are thus eliminated.

The command block has the role to control the charge level of batteries and also to assure the commands for the power semiconductors throughout the conversion process.

\subsection{Mobile systems of energy storage}

Vehicle to grid systems allow energy to flow from the grid to the car batteries and back to the grid. These systems can be used to balance the fluctuation between energy storage and energy consumption.

Consequently, when the generator is in operation, the vehicle is not in a pollution-free mode, which, to the dismay of many, is therefore not compliant with the aim of zero$\mathrm{CO}_{2}$ emission.

The development of electric vehicle is based on electric batteries with large capacity and their well determined time usage has led to considering the use of the energy stored in the batteries as reserve sources for the power grid system when necessary. The charging of batteries during the night can even ensure flattering of the load curve. When the generator is in function, the vehicle is not in a pollution-free state, that is not compliant with the aim of zero- $\mathrm{CO}_{2}$ emission. [6] Car batteries can be used for energy storage for use in the grid, especially where the grid is supplied by a higher percentage of intermittent, renewable energy sources. The excess of wind and solar energy can thus be stored to the car batteries and released back when necessary. [7]

Electric vehicle use in conjunction with energy operators assures:

- the management of batteries charging process;

- optimal use of car battery stored energy as energy source for supporting the grid demand;

- achieving the best price for electrical energy.

In figure 2 there are indicated two opportunities for charging electric vehicle batteries: from the local grid, or from an aggregator which assure the management process and the relationship with the energy supplier. When the energy production and energy consumption are balanced, the car batteries can be used as energy sources in case of intermittent energy spike demands.

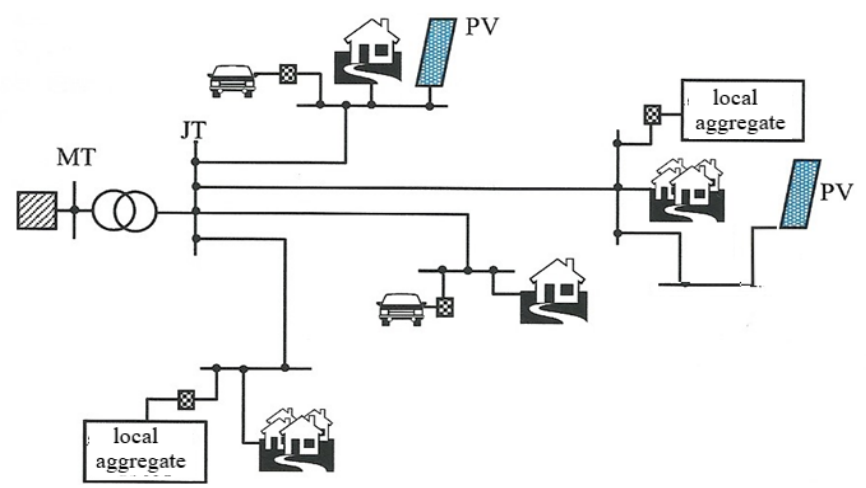

Fig.2. The scheme for a possibly distribution grid 
The redundant energy from photovoltaic and wind sources can be stored in the car batteries and released back to the grid when is necessary. Nowadays, communication systems and intelligent control and measurement systems offer the necessary data to aggregators for providing optimal services to electric vehicle owners [2].

\subsection{Operation of energy storage systems within the electric power market}

The energy storage systems have an important role as:

- $\quad$ tool for flattening load curve (figure 3);

- $\quad$ being a predictable load by in aggregation with less predictable energy sources;

- $\quad$ sources of energy for short time demands arising in the utility.

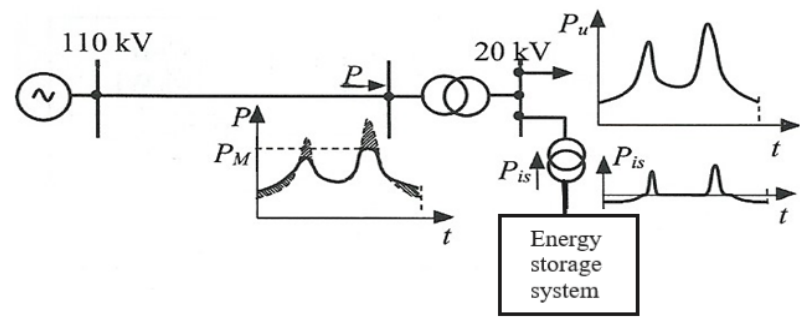

Fig.3 Scheme of energy storage system role

In the table 2, is showing the energy storage opportunities and their applications. The large energy storage capacities can assure the energy supply for the utility in case of black down events.

Table 2. Opportunities of energy storage

\begin{tabular}{|c|l|c|c|c|}
\hline Application & \multicolumn{1}{|c|}{ Technology } & $\begin{array}{c}\text { Power } \\
{[\mathbf{M W}]}\end{array}$ & $\begin{array}{c}\text { Time } \\
{[\mathbf{h}]}\end{array}$ & Cost [euro/kW] \\
\hline \multirow{4}{*}{$\begin{array}{c}\text { Large storage } \\
\text { Capacitors }\end{array}$} & CHEAP & & 10 & $1400-4100$ \\
\cline { 2 - 5 } & CEAS & $100-300$ & 10 & $1000-2300$ \\
\cline { 2 - 5 } & CEAS & $30-50$ & 6 & $1600-2650$ \\
\cline { 2 - 5 } & Li-ion & $30-50$ & 6 & $2000-3100$ \\
\cline { 2 - 5 } & Lead accumulator & $30-50$ & 6 & $2250-3900$ \\
\cline { 2 - 5 } & NaS & $30-50$ & 6 & $2150-3900$ \\
\cline { 2 - 5 } & Li-ion & $50-100$ & 4 & $1300-2150$ \\
\hline \multirow{3}{*}{$\begin{array}{c}\text { Support of } \\
\text { distribution grid }\end{array}$} & CAES & $10-20$ & 4 & $1850-2740$ \\
\cline { 2 - 5 } & Li-ion & $10-20$ & 4 & $1450-3500$ \\
\cline { 2 - 5 } & Lead accumulator & $10-20$ & 4 & $1800-3000$ \\
\cline { 2 - 5 } & NaS & $10-20$ & 6 & $2240-3520$ \\
\cline { 2 - 5 } & Li-ion & $1-5$ & 2 & $1000-1600$ \\
\hline \multirow{2}{*}{$\begin{array}{c}\text { Frequency } \\
\text { case of fault }\end{array}$} & Li-ion & 20 & 0,5 & $450-950$ \\
\cline { 2 - 5 } & Flywheel & 20,5 & $650-1600$ \\
\hline \multirow{2}{*}{} & & & & \\
\hline
\end{tabular}

The capacity of these storage systems is similar with the power capability of some power plants form National Electric System (SE). The time necessary for the storage system to fulfil the load demand should be correlated with duration for restarting the thermoelectric power plant [8]. The storage systems which assure support for transmission and distribution grid, are also operating to compensate some load disturbances in the local grid or to modify the power flow in case of sudden demands or voltage reductions $[9 ; 10]$. The storage systems are also working for covering the short duration load demand, for 
example in case of defects in Electrical System grid, until some back-up sources are being started (like hydropower plant with pumping accumulation).

\section{Conclusions}

Providing the necessary energy under the constraints of reducing the emissions of pollutant substances and rapid exhaustion of fossil fuel reserves, represents a great current challenge for the world.

The key to overcome this challenge is to pair the renewable energy sources with energy storage solutions. The energy storage systems assure several features from the point of view of their use in the energy: for frequency adjustment, the storage systems can assure essential services on electric system stability; the large power storage systems can be coupled with less predictable energy supply sources, getting an ensemble of predictable system to fulfil the load demand even when demand exceeds its generating capacity and supplies energy to the grid when the energy production from renewable sources is reduced, this type of aggregate is operating as a controllable source in the electricity market; the large power storage sources can also assure flattering of the load curve when connected to disturbances producing customers; the storage sources can assure the system services by providing necessary energy when the main energetic group is disconnected, as the large power storage sources can assure the optimal power flow in the electrical system.

\section{References}

1. V. Musatescu, s.a., Bazele tehnice si economice ale pietelor de energie electrica, Editura Agir, Bucuresti (2019)

2. $* * *$ https://www.bizzyday.ro

3. N. Golovanov,s.a., Surse regenerabile de energie in sistemul electroenergetic, Editura Agir, Bucuresti (2015)

4. L. Matthew, s.a., Oxygen-Based Anion Redox for Lithium Batteries, ACS Publications

5. S. Arad, Surse regenerabile, teorie si aplicatii, Ed. Focus Petrosani, (2015)

6. J.J. Hwang, J.S. Hu, C.H. Lin, A Novel Range-Extended Strategy for Fuel Cell/Battery Electric Vehicles, (2015)

7. Timo Lehtola, Ahmad Zahedi, Sustainable Energy Supply Using Renewable Sources Supported by Storage Technology, IEEE Innovative Smart Grid Technologies - Asia (ISGT-Asia) Melbourne, Australia, (2016)

8. M.D. Stochitoiu, M. Marcu, I. Utu, T. Niculescu, F.G. Popescu, Proceedings of the 18th International Multidisciplinary Scientific Geoconference SGEM 2018 18, 591-596 (2018)

9. *** https://www.renewable-ei.org/en/statistics/international/

10. *** ABB Energy Efficiency Handbook, Power Generation Energy Efficient Design of Auxiliary Systems in Fossil Fuel Power Plant, (2010) 